\title{
Dialogic pedagogy and semiotic-dialogic inquiry into visual literacies and augmented reality
}

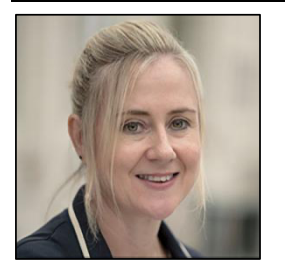

Zoe Hurley

Zayed University, Dubai

\begin{abstract}
Technological determinism has been driving conceptions of technology enhanced learning for the last two decades at least. The abrupt shift to the emergency delivery of online courses during COVID-19 has accelerated big tech's coup d'état of higher education, perhaps irrevocably. Yet, commercial technologies are not necessarily aligned with dialogic conceptions of learning while a technological transmission model negates learners' input and interactions. Mikhail Bakhtin viewed words as the multivocal bridge to social thought. His theory of the polysemy of language, that has subsequently been termed dialogism, has strong correlations with the semiotic philosophy of American pragmatist Charles Sanders Peirce. Peirce's semiotic philosophy of signs extends far beyond words, speech acts, linguistics, literary genres, and/or indeed human activity. This study traces links between Bakhtin's dialogism with Peirce's semiotics. Conceptual synthesis develops the semiotic-dialogic framework. Taking augmented reality as a theoretical case, inquiry illustrates that while technologies are subsuming traditional pedagogies, teachers and learners, this does not necessarily open dialogic learning. This is because technologies are never dialogic, in and of themselves, although semiotic learning always involves social actors' interpretations of signs. Crucially, semiotic-dialogism generates theorising of the visual literacies required by learners to optimise technologies for dialogic learning.
\end{abstract}

Key Words: Dialogism / signs / semiotics / questioning / opening / augmented reality / technologies

Zoe Hurley (PhD, Lancaster University, UK) is the Assistant Dean for Student Affairs in the College of Communication and Media Sciences at Zayed University, Dubai, United Arab Emirates. Zoe teaches undergraduate courses in social media and new media writing. She is interested in semiotics, dialogism and questions of power in technology enhanced learning. She has published academic papers on Arab women's social media, postdigital living and online learning during COVID-19.

\section{2ds}

\section{Introduction}

\section{Dialogism, semiotics and signs}

Technological tools come and go. According to big tech, augmented reality (AR) is the latest application to enhance pedagogy (Adobe, 2020). But this theoretical inquiry responds to the need for philosophically grounded perspectives of what we mean by learning and the extent to which pedagogies involve visualities. Visuality is a central aspect of human consciousness, for those who can see in physical terms, but also for those are partially sighted or blind and 'see' at abstract, conceptual and imaginary levels. Visuality represents a gap in western philosophical traditions, which tend to be logocentric and glottocentric accounts of knowledge, fixated on the spoken and/or written word. To address the lacuna, I draw on the 
dialogic perspective of the literary scholar Mikhail Bakhtin (1984) suggesting that language is multivocal, social and in process. While Bakhtin saw the word as a bridge to thought, his theory of dialogism has strong correlations with the semiotic philosophy of the American pragmatist Charles Sanders Peirce $(1839-1914)$ (Petrilli, 2017). Semiotics is the theory of meaning making occurring through signs. Signs include the codes, images, sounds, texts, gestures, hashtags, or anything conveying meaning and so visuality is central (Semetsky \& Stables, 2014). While neither Bakhtin nor Peirce developed a specific theory of dialogic education, both provide a strong dialogic philosophy of living via the heteroglossia of signs.

To trace the links between Bakhtin's dialogism with Peirce's semiotics, as well as their promise for facilitating dialogic pedagogy for visual literacies, this paper develops theorising of visual dialogic perspectives of learning. Inquiry explores notions of visual literacies conceptualised through the dialogism of semiotics. This is important because it problematises assumptions that literacies and technologies are necessarily dialogic. The specifically semiotic-dialogic framework takes augmented reality as a theoretical case and asks: To what extent does semiotic-dialogism help to conceive of the visual literacies of augmented reality?

This is a complex theoretical question spanning semiotics, dialogism, visual literacies and augmented reality. Consequently, this complexity could generate conceptual insights into the types of visual literacies required by learners using technologies like AR. These are vital for developing new vocabulary, discussions and frameworks for semiotic-dialogism. To illustrate further, I begin with a review of relevant literature.

\section{Literature review}

The review of literature is organised across these domains of dialogism, semiotics, visual literacies and AR. This thematic theoretical review helps to conceptualise semiotic-dialogism and its theoretical scope for inquiry into visual literacies, AR and the role of immersive visual technologies in learning. Thematic searches were carried out in databases and Google Scholar's search engines. Presentation of the literature is thematic, rather than chronological, since the study is not concerned with a teleological perspective of visual literacies and augmented reality but rather the potential of semiotic-dialogic inquiry for disrupting earlier normative theorising.

\section{Dialogism}

Dialogism is defined as the exchange of perspectives and voices (Bakhtin, 1986). It involves the interaction of texts, aesthetic genres and interpretors and has also been developed to conceive of learning as a range of perspectives and voices in social interaction (Matusov, 2009). The term 'dialogue' is derived from two words in classical Greek, 'dia' meaning 'through' and 'logos' meaning 'word' or 'discourse.' Dialogic education has been defined as engaging students in an ongoing process of shared inquiry (series of questions) through dialogue (Wegerif, 2017). Learning can be understood as shared dialogic space, coconstruction of knowledge through questioning. As argued by Bakhtin, "If an answer does not give rise to a new question from itself, it falls out of the dialogue" (1986, p.168). This suggests that dialogic education is an ongoing process, series of interactions for different points of view rather than a transmission of facts.

Freire, another key figure of dialogic pedagogy, suggests that dialogue is an "essential necessity" facilitating humans in achieving "significance" (1970, p.69). To engage in dialogue, words play a dualistic role that involves the enunciator in both reflection and action. Freire says, "There is no true word that is not at the same time a praxis. Thus, to speak a word is to transform the world" (1970, p.68). This indicates that dialogic pedagogy promotes learners' agency critical examination of the self, life and the world (Matusov \& Marjanovic-Shane, 2017; Matusov, von Duyke \& Kayumova, 2015). From a dialogic pedagogy perspective, 
theorists like Freire (1970) suggest that education can only be considered dialogic, and thereby as having significance, when learning is collaborative and provides openings for transformation and praxis. Freire (1970) views the social systems and processes of learning as ontologically inseparable to the individual and learning and subjectivity are inter-subjective. This is a constructivist position viewing learning as occurring when social actors collaborate to construct meaning via multidirectional dialogue. Freire (1970) contested individualised accounts of education, that are intra-subjective and assume knowledge can be downloaded, as a banking or deposit approach to learning. In terms of deconstructing dialogism at the level of words, signs or codes, Freire explains:

Dialogue cannot be reduced to the act of one person's 'depositing' ideas in another, nor can it be a simple exchange of ideas to be 'consumed'....Because dialogue is an encounter among men and women who name the world, it must not be a situation where some name on behalf of others (1970, p.70).

Matusov, however, asks significant questions about Freire for "uncritically and willingly" participating in totalitarian communist regimes in Africa, including Guinea-Bissau and in Sao Tome and Principle in the 1970s, while failing to adequately challenge these regimes (Freire, 1978; Freire \& Macedo, 1987)" (2009, p.73). Matusov describes Freire's approach as "weak dialogism" since it is an instrumental approach, that can be "dosed, scheduled, and well located in the classroom" (2009, p.75). While for Matusov there is nothing inherently wrong with dialogic instrumentalism he suggests the issue is confusing "dialogicity, how dialogic the discourse is, with the genre of discourse" (2009, p.75), since this could lead to prescriptive pedagogy that has no implications beyond the classroom. Alternatively, "strong dialogism" indicates that "genuine education cannot survive without dialogue" (Matusov 2009, p.76).

Within radical strong dialogism, pedagogy is epistemologically underpinned by reflective knowledge rooted in dialogue and ontologically through locating dialogue at the centre of human activity. Matusov (2009) suggests Freire's dialogic pedagogy does not go far enough in integrating a reflective epistemology with a dialogic ontology. While I do not disagree with Matusov's critique of Freire's evident theoretical and political inconsistencies, Freire also spoke many times of the need to contextualise his ideas while never claiming to have a specific 'method,' or even a set of methods with universal applicability (Roberts, 2003). In his later works, for example Pedagogy of Freedom, Freire (1998) also provides a distinctive approach to the politics of education and a voice of hope for teachers who remain committed to their vocation under less-than-ideal circumstances (Aronowitz, 2015; Roberts, 2003). Nevertheless, Matusov $(2009 ; 2020)$ attunes us to the multicultural hybridity of varying pedagogical situations. This indicates the importance of considering the extent to which learners and theorists are always constrained within broader socio-political contexts and that agency is entangled within a series of cultural, historical, political, material and technological phenomena. This could enable us to explore a spectrum of learners across a variety of geo-political environments rather than exclusively in terms of apparently ideal learning environments that are already optimised for dialogism.

Bakhtin (1999) also articulates that the diverse multicultural aspects of human activity that involve dialogic language. He suggests that these aspects are utterances that are shaped by the conditions in which they are produced and, simultaneously, by the goal of these structures. The compositional aspects of speech genres are therefore determined via their thematic content, structure and purpose. In other words, speech genres are a dynamic interplay of what is being said, how it is presented and to what purpose. These genres are thus also infinitely heterogenous since social actors and the boundaries of human activity are in constant process, change and interpretation. Bakhtin's (1999) theory of speech genres has specific parallels with Peirce's (1908) theory of semiosis. Both theorists define meaning making as occurring 
through the interconnections of form, content, purpose and the further generation of chains of meaning and action.

\section{Peircean semiosis}

For Peirce (1908) the semiosis of meaning involves the triadic sign-action of Representamen (signs or words, pictures, gestures, mental images or any phenomena communicating meaning) with Object(s) (what the signs refer to) and processes of Interpretant (practices of interpretation and orientation towards further meaning production) (Stables et al., 2018).

This offers a sophisticated framework for exploring the dynamic relations of knowledge and learning in terms of processes of dialogic communication (having information as a product and understanding as an effect), a universe of discourse or common sense (having community as a product and sensibility and comprehensibility as effects), and processes of enquiry (having consensus as a product and reasonableness as an effect). For Peirce (1931), knowledge is "a living historic entity." It is acquired through experience and mediated through the dialogism of signs (Strand, 2010).

Both Bakhtin and Peirce are therefore aligned through their dialogic epistemology suggesting how knowledge occurs within fluid and dynamic processes of communication. Susan Petrilli, (2017) also suggests that Peircean semiotics corresponds with Bakhtin's $(1986 ; 1999)$ theory of dialogism since it suggests that signs, and their interpreters, enter a process of dialogic or hybrid interaction. In this paper, I build on these alignments to suggest that Peirce's triadic conception of meaning making is a dialogic theory. This is because it conceives of social actors' sign-actions occurring through intertextual semiosis and dialogic interpretation. I propose that understanding the sign-driven processes of semiosis, as specifically dialogic, could contribute to expanding our conceptions of dialogic pedagogy in semiotic terms. This might help to go beyond transcendental perspectives of what 'true dialogic pedagogy' should be while situating variations of weak and strong dialogisms in terms of their cultural historical context (Matusov, 2009).

However, Peirce's philosophy of signs extends far beyond words, speech acts, linguistic and literary genres and indeed human activity. For Peirce, meaning through signs is constituted via the triadic semiosis of signs, objects and interpretations occurring consecutively. This sense of semiosis cuts across the Cartesian divide of mind and body through locating signs as the defining vehicle and mediators of social consciousness within a broader semiosphere or universe of signs (Lotman, 2005 1990; Olteanu, 2015). Furthermore, social actors are themselves signs who incorporate a language of signs, via and as signs, within a biosemiotic or sign-driven environment. Learning involves the interpretation of abstract, conceptual, material, social, emotional, physical and technological signs. Signs are all around, within and in-between social actors and sign-driven consciousness of, about, embedded and embodied within the world. Bringing a Peircean semiotic perspective to dialogic pedagogy therefore broadens the discussion from linguistics, culture and constructivism to consider the dialogism of a sign universe.

Nevertheless, this framework retains the Bakhtinian structure of content, form and purpose as meanings are understood as semiotic-dialogic interplays while also helping to extend sign-actions within a varying range of contexts, environments and technological locales. The semiotic-dialogic framework therefore has great potential for conceptual multicultural hybridity (Olteanu, 2019). Furthermore, it departs from a transcendental, universal or idealist perspective about what dialogism and dialogic pedagogy should, could or would be. In the next section, I will discuss the significance of the semiotic-dialogic pedagogic framework for theorising the concept of visual literacy and AR in this case study. 


\section{Visual literacies}

In terms of visuality, what we see and do not see are mediated via histories, cultural values, ideologies, social practices and technologies (Mirzoeff, 2006). This indicates that seeing is not simply the ability of an individual, all seeing Cartesian subject (Jay, 1988). Consequently, there has been a visual turn in scholarship and a growing interest in visuality due to the increasing proliferation of images across visual mediums like social media. Yet, as scholars of visual arts, cinema, cultural studies media and communications have been arguing for decades, visuality and the role that it plays in our society is arguably nothing new. However, theories of visuality within educational research represent a longstanding gap within scholarship (Lacković, 2020). But to understand the impact of visual technologies, for instance AR, we need to take visuality and its role within pedagogy seriously. Taking visuality seriously involves thinking about contemporary ways to definine visual literacy which in turn will help to consider AR in visual terms as well as the visual literacies involved.

Visual artefacts have been used throughout human histories. The concept of 'visual literacy,' despite the terms' modern connotations, is nothing new (Pettersson, 1989). Ancient philosophers, including Aristotle, Socrates, and Plato used images for visual communication. Across all religions, teachers and prophets have used metaphors to help their listeners create inner images (Pettersson, 1989). In the twentieth century, the need to take the role of visuals seriously in education has been a concern since the 1930s (e.g., Hoban, Hoban and Zissman's, 1937, Visualising the Curriculum). The term visual literacy has been debated since the 1960s. It is considered to have been coined by John Debes, co-founder of the International Visual Literacy Association. Debes explained:

Visual literacy refers to a group of vision competencies a human being can develop by seeing and at the same time having and integrating other sensory experiences. The development of these competencies is fundamental to normal human learning. When developed, they enable a visually literate person to discriminate and interprete the visible actions, objects, and symbols natural or man-made, that he encounters in his environment. Through the creative use of these competencies, he is able to communicate with others. Through the appreciative use of these competencies, he is able to comprehend and enjoy the masterworks of visual communication (1969, p.26).

This citation indicates that Debes viewed visual literacy as "competencies," and as something possibly fluid while the definition unwittingly reinscribes aesthetic judgements about ways of seeing. But aesthetic judgements may conflate with technological determinism and solutionism, which influences notions of visual literacies. Simultaneously, the definition alludes to the complexity of visuality and density of visual regimes in anthropocentric societies. However, it tacitly implies a top-down visual hierarchy, or that there are certain visual forms or "masterworks" that the visually literate subject should aspire to "comprehend and enjoy" (Debes, 1969, p.26).

The role of visuality within learning and higher education is also not necessarily something topdown or to be developed in order to 'read' aesthetically dominant social values.

Alternatively, visual literacy can be conceived in semiotic-dialogic terms, coming from within and outside the academy. Conceptions of visual literacy could thus differ, not only according to the cultural, geopolitical and environmental learning context, but in terms of academic discipline, vernacular practices and expressions, social actors' individual differences, modes and architectures of technologies. Other visual scholars indicate that our gaze is trained in psychological, cultural and historical terms and thus visual literacy is not a naturally occurring competency, acquired through frequently encountering images of various kinds (Mirzoeff, 2006). However, while visual literacy definitions mostly use a metaphor of visual reading 
and writing, not all visual skills easily undergo this categorization (Kędra, 2018). This tendency may further indicate that visual literacy is a failed metaphor, as already suggested by Cassidy and Knowlton (1983). From a semiotic-dialogic perspective, it is also rooted in essentialist notions of what visual literacy already is, could and should be.

Conversely, semiotic-dialogic theorising suggests that meaning occurs through semiosis as the learner simultaneously processes the signs (words, images, visual, multimodal components); objects (sign references); and interpretants (immediate, dynamical and final interpretations). The learners' interaction with the signs, words and images, within their environments, are the mediating trigger for the interpretive process. Next, I discuss the implications of these theorisations for considering AR and its potential role in pedagogies.

\section{Augmented reality}

AR is currently configured through a range of technological codes, semiotic and multimodal resources. This includes the combinations of video, text, visual effects, animated objects, shapes, emojis and filters that can be overlaid on surfaces and objects and viewed via mobile devices. Virtual reality (VR) - involving headsets and AR - which can be used on mobile devices) tend to be marketed as similar visual attractions although they are slightly different. Semiotic-dialogic perspectives of visual literacy might help to review and critique how $A R$ is understood. Approaching visual literacy from a semiotic-dialogic perspective can help to embed visual artefacts within social and material practices. Semiotic approaches have been used in film studies and audio-visuality studies. In terms of AR, it helps to locate it as a novel artefact that generates visual curiosity. This is like the curiosities found at fairgrounds and theatres in the $19^{\text {th }}$ century, whereby spectators would view visual attractions or marvels for the eye which seemed to challenge our entire concept of reality and visual perception.

The first example of AR (like VR) was developed as a headset. It was called the 'Sword of Damocles' and created in 1968 by computer scientist Ivan Sutherland, with the help of his students at MIT. In 1966, Sutherland and his colleagues performed what are widely believed to be the first experiments with head-mounted displays of different kinds. They called the AR headset the Sword of Damocles to refer to the allegory of Cicero's tale of Dionysius and Damocles. This is the story of the King who gave his riches and privileges to his courtier. Once the courtier was in a position of power, he noticed the razor sharp sword hanging from the ceiling. This represents the idea that those in power always labour under the specter of anxiety and the burden of power in being an all seeing all knowing social actor.

This view of $A R$, as having huge empowering potency, has been aggressively promoted by the tech industry and marketeers. For instance, AR and emerging tech expert John Werner explains "why this emerging field has the power to give all of us Superpowers." In a TED Talk Werner (2019) suggests that instead of being presented on flat screens, people could be rendered in AR. This closely resembles the famous Star Wars hologram scene featuring Princess Leia decades ago, when she is rendered for ObiWan Kenobi. Werner tells audiences that AR rendering will increase productivity and "make sure people are paying attention." Coincidently, Werner serves as Managing Director and Partner at Link Ventures, and as Chief Network Officer, SVP Corporate Development of Cogo Labs. Co-founder of Citizen Schools, an advisor for PhotoButler, Vestigo Ventures and Founders Forum (Boston). Werner is strategically positioned to promote technology driven education and Citizen Schools has recently partnered with major financial institutions including the Bank of America and technology corporations like Google who have made major financial investments in addition to leading a variety of apprenticeships (MIT, 2021).

While Werner has direct economic interests in promoting AR pedagogies, researchers without vested incentives, including Maximilian Speicher working out of the AR research lab at University of 
Michigan. Speicher (2018) suggests AR has been overly hyped, and there is a lack of real uses so far. Speicher says, just as people turn off AR in "Pokémon GO," he has "never seen or heard of anyone actually using AR applications such as IKEA's furniture app as it's allegedly intended; the app has just 3,100 reviews in Apple's app store, far fewer than the 104,000 for Pokémon GO." Speicher (2018) questions whether AR will be commonplace in five years, or whether AR glasses will replace smartphones within a decade.

Semiotic-dialogism could therefore be vital in helping to develop critical and pedagogically informed responses to corporations' aggressive promotion of technology driven learning. This is important because as educators we should not facilitate tech companies' profit driven encroachment on education at the cost of learners and learning, especially when these views are not underpinned by pedagogy. As AR is likely to be established within education, pedagogical theorising needs to get a handle on what it is and explore theoretical frameworks for responding and shaping a critical response. One such possible response is semiotic-dialogic pedagogy. As the author of this article, I realise that the term and configuration seem loaded with jargon. But complex theorisations are necessary for grasping the oblique visual and social aspects of $A R$ and what it means for learning. This brings us back to the central questions of the study asking: To what extent does semiotic-dialogism help to conceive of the visual literacies of augmented reality? To address this question, I outline the theoretical framework of the study.

\section{Semiotic-dialogism}

Theorising AR from the semiotic-dialogic perspective suggests that meaning making via AR technologies would involve not only the technological or fixed affordances of AR but also processes of semiosis. Once the learner activates the AR trigger, through their mobile phone or another device, the semiosis of sign-driven meaning making is also triggered. Yet, this is never a purely technological mediation or one-way transmission since it involves the interplay of signs, AR technological features, dynamics and interpretative mediations of the AR user or learner. This view suggests that neither AR technologies nor learners exclusively mediate meanings but, rather, that learners and technologies simultaneously engage as, with and through living codes (Freire, 1970). Semiosis could therefore be considered as a dialogic opening whereby technological, sign-driven, social actors and textual mediations interconnect through, with and around AR or other technologies. The interplay of learners, text, AR, or living code, interconnecting through dialogic semiosis are illustrated in Figure 1:

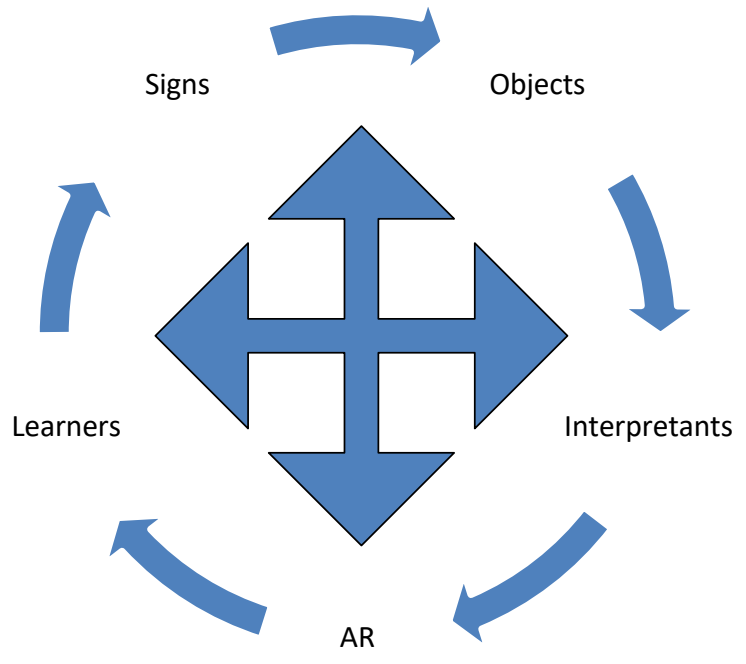

Figure 1: Dialogic Semiosis 
In terms of semiotic-dialogic theorising, Figure 1 indicates that the circular and multidirectional interactions of learners, AR, sign, object and interpretant occurring simultaneously. Dialogic semiosis is represented here as technological, semiotic and dialogic interconnections of living codes. This semioticdialogic framework also illustrates dialogic semiosis as a possible pedagogic opening of living codes that could be defined, not only in constructivist terms, but also as assemblage of linguistic, cultural, technological and situated meanings that social actors make out of sign phenomena. This semiotic-dialogic approach could possibly go beyond the pitfalls of objectivism and constructivism, rendering the sign-user as either passive recipient or an omnipotent creator of meaning (Bergman, 2009). The semiotic-dialogic conceptual framework is broad enough to theorise the intersecting issues of semiotic-dialogic agency in relation to uses of AR visual literacies and pedagogies. Semiotic-dialogism also suggests that all constructions of knowledge are socially located, Simultaneously, I am self-reflexive of my role as the analytic instrument in constructing this theoretical narrative. Next, I briefly discuss some of the issues of author self-reflexivity and its role in this theoretical inquiry.

\section{Self-reflexivity}

The concept of self-reflexivity stems from the early twentieth century American pragmatist philosophy (Dewey, 1922). Self-reflexivity as a sociological theory was developed to understand the social individual (Mead, 1934). It is also a prescient value of qualitative research, requiring authors to reveal their subjectivity and motivation for conducting studies. I am thus self-reflexive that all research can be considered as a narrative that occurs within the social context but also gender, racial and socioeconomic positioning of the researcher (Denzin, 2001). Scholars need to have self-reflexivity and ask questions about their own positionality and I therefore discuss my positionality next.

Originally from the United Kingdom, I am international woman academic who has been teaching at a university in Dubai since 2013. I began researching augmented reality in 2014, while embedding AR as part of undergraduates' project-based learning in media studies and literacy classes in Dubai (Hurley, 2016). Teaching students for whom English is a second language raises my awareness of the need to develop deeper understandings of visual literacies as well as dialogic conceptions of technology enhanced learning. Iterations of my research included empirical research into the uses of AR applications like the now obsolete Aurasma. In these empirical studies, I found Aurasma difficult to use, and technical issues deflected from learners' social interactions. I also struggled to learn and teach students how to use Adobe's AR software application Aero. Adobe's marketing suggests Aero is accessible and intuitive (Adobe, 2020). But my students and I found Aero's technological tools challenging and confusing. As a result of these empirical observations, I became aware of the need to ask critical and theoretical questions about the visual literacies surrounding AR, especially in view of the disconnect between AR's pedagogic challenges and aggressive marketing by big tech. Next, I provide further discussion of the relevance of semiotic-dialogic perspectives of AR visual literacies.

\section{AR visual literacies}

A substantial area of the pedagogic literature emphasises the psychological and motivational factors of AR (Solak \& Cakir, 2015; Di Serio et al., 2013). This indicates the value of entertaining learners through play, technology and the novelty value of AR. A number of these studies make the problematic generalisation that learners are "digital natives" (Martín-Gutiérrez et al., 2014). This assumption indicates their uptake of AR, and its integration with pedagogy, will be intuitive and automatic. Other studies indicate the pedagogic affordances for increasing reading comprehension (Ivanov \& Ivanov, 2015), concretizing abstract concepts (Dori \& Belcher, 2005) and the development of critical thinking (Dunleavy, Dede, \& Mitchell, 2009). This positions AR technology as being a virtual black box of embedded affective factors and tools for improving academic reading and learning. However, from a dialogic pedagogy perspective, 
what is the value of these technological affordances if they are not dialogic and do not contribute to further generation of questions or meanings? From a dialogic perspective, if there are no openings for critical reflections, praxis, transformation or further generation of meaning, semiotic-dialogic pedagogy is not occurring. These uses of AR could possibly, therefore, merely be reinforcing pedagogic hegemony as a one-directional transmission of information. These thin descriptions of pedagogy and AR in much of AR pedagogic scholarship also, arguably, lack detailed epistemological and theoretical frameworks for establishing specific understandings of learning, the integration of learning with AR or semiotic-dialogic pedagogy.

Nevertheless, Mahadzir and Phung (2013) attempt to provide a more substantial framework for discussing AR's affordances for academic reading. They suggest AR increases students' performances by providing an inspiring learning environment and contributes to, perceptual arousal, enquiry arousal, variability, goal orientation, motive matching, familiarity, learning requirements, success opportunities, personal control, intrinsic reinforcement, extrinsic rewards, and equity. While the AR contribution to perceptual arousal and enquiry arousal could potentially lead to semiotic-dialogic question formations, Mahadzir and Phung's (2013) focus on fixed affordances leaves little scrutiny or discussion of the limitations, cultural or individual differences or the ways in which AR could contribute to dialogic pedagogy. Dunleavy, Dede and Mitchell's (2014) perspective of AR rectifies this to a certain extent. They suggest that $A R$ can be viewed as a cognitive tool, when combined with pedagogical approaches, and situated within constructivist learning theory. However, they acknowledge that although AR has cognitive and constructivist affordances, its limitations include cognitive overload and the challenge of integrating and managing the overall AR experience from teachers' perspectives. I therefore suggest that this perspective does not necessarily provide a convincing rationale for a constructivist stance and privileging the teacher's role in pedagogy cannot be aligned with dialogic pedagogy (Matusov, 2009).

Semiotic-dialogic theorising of multimodality, and sign-driven interconnections of AR, could be crucial for conceptualising its impact upon pedagogy (Hurley, 2018). Means (2018) contests the discourses of technological solutionism surrounding higher education or the idea that merely having technology in the classroom is making it better. Readers of the Dialogic Pedagogy Journal (DPJ) will be aware that learning involves more than a direct transmission of information from a teacher and nor is it one-way (Cresswell, 2016). However, too much of the literature surrounding AR is underpinned by versions of technological solutionism which invests tech with the power to transmit knowledge. Similarly, across scholarship surrounding the role of technologies in higher education, there are underlying assumptions that technology, while potentially removing the teacher from the learning equation, can digitally deposit knowledge much like buying a product from a vending machine (Hurley, 2021). This implies that cognitively complex and social processes of learning are somehow downloadable and consumable. However, while this narrative helps tech companies to capitalise on higher education, schooling and social learning, dialogic pedagogy could provide an increasingly important counter narrative to technological solutionism and marketized versions of learning. It could also help to theorise some of the limitations of technologies in higher education. For example, how they might inhibit learner agency and critical examination of the self, life and the world.

AR enables a combination of audio-visual elements to be captured through a camera on a mobile phone and combined with multi-media elements including texts, images, video, 3D models and animations (Martín-Gutiérrez et al., 2014). The ways in which AR are currently configured through a range of technological semiotic resources, including audio, video, text, hashtags, hyperlinks and filters, technologies provide learners with a mixture of communication tools and meanings that require clearer articulations of the impacts upon learning, agency and the extent to which they are semiotic and dialogic. Martín-Gutiérrez et al., (2014), for example, suggest that AR contributes to computer supported collaborative learning which is a pedagogical approach that can be used for deploying educational apps based on AR in higher 
education. They suggest that "outdated teaching creates barriers for some students that are used to interacting with modern technological gadgets and computers" (Martín-Gutiérrez et al., 2014, p.760). However, their definition of collaborative learning, why AR could support it or what they mean by pedagogic 'barriers' remains thin.

Conversely, this study's semiotic-dialogic framework offers a redefinition of AR technologies within higher education. This articulates semiotic-dialogic learning as diverse generations of meaning making that are central to learners' agential interpretations of living codes. The next section applies semiotic-dialogism theorising to first-hand experience with AR.

\section{First-Hand Experience with AR in a Classroom}

First, my experiences with AR in classrooms in Dubai indicate that semiotic-dialogism contradicts the literature surrounding AR pedagogy and claims that learners are highly motivated by AR technologies (Solak \& Cikir, 2015; Di Serio et al.,2013). This discrepancy could possibly be because the novelty of technologies is reaching a saturation point in the lives of these participants. Nevertheless, AR pedagogy appears black boxed in most of the literature since there are limited insights into specific learning strategies or thin descriptions of how AR actually promotes the development of vocabulary, new concepts, dialogue and further generation of meanings.

Second, semiotic-dialogic theorising suggests that the platform architectures, and mediations of the AR apps, like the now obsolete Aurasma, are not necessarily intuitive for learners and technological mediations can take precedence over semiotic-dialogue, transformation, praxis and new meanings. My experiences with students suggest that AR does not automatically facilitate semiotic-dialogic hybridity or agency. On the contrary, AR could limit opportunities for learners' dialogic interpretants. This is because AR could atomise or distance learners from one another while users are technologically sealed off in their own immersive AR bubbles.

These experiences can be summarised as pointing towards the lack of understandings of the motivations and applications of AR within pedagogy; the non-intuitive aspects of AR for learners; and possible barriers that AR pedagogy presents to semiotic-dialogic pedagogy. A further strong feature, coming through the aligned perspectives of Bakhtin (1986) and Peirce (1878), is that dialogic learning should involve questions, new words and generation of meaning making. However, AR is not necessarily intuitive for learners as not all young people can be considered 'digital natives.' Moreover, we cannot assume that learners intuitively know how to ask dialogic questions. AR, like other technologies, involves trial and error but this does not necessarily provide dialogic in-roads to developing critical and conceptual questions about the world. Conversely, for pedagogy to facilitate semiotic-dialogism it should be motivated by learners' dialogues that expand agency, critical examination of the self, life and the world. Uses of AR, or other technologies, in and of themselves, are not necessarily dialogic pedagogic solutions since they can also be barriers to semiotic-dialogism. Next, I offer some conclusions, limitations and recommendations of the inquiry

\section{Conclusions, limitations and questions for future semiotic-dialogic studies}

The study explored semiotic-dialogism's scope for conceiving AR visual literacies. Theorising indicates that technologies, including AR, are not necessarily dialogic in and of themselves. Arguably, merely putting the AR technology into learners' hands does not simply facilitate critical examination of the self, life and the world. This, however, does not imply that AR cannot be integrated with dialogic pedagogy but rather learners and teachers need to develop semiotic-dialogic vocabularies surrounding technologies. The semiotic-dialogic framework therefore returns the reader to some of the pivotal tensions or gaps 
underlying AR scholarship from a dialogic pedagogy perspective. Theorising reveals the need to go beyond some of the broad-brush assumptions surrounding learning in AR pedagogic literature. It also problematises the automatic promotion of technologies, whether in the classroom or beyond, when learning is perceived as transmission of knowledge. Alternatively, the semiotic-dialogic perspective of semiosis suggests learning is always interpretive.

Importantly, theorising indicates that expanding conceptions of dialogic pedagogy, from a semiotic perspective, could expand a consideration of learners' mediations through sign practices. This extends notions of visual literacies as written and spoken discourse and helps to locate semiotic-dialogic pedagogy within situated contexts. It considers the hybridity of dialogism across multicultural spectrums, in relation to a variety of learners and beyond anthropocentrism (Hurley, 2019a; 2019b; 2021). However, I am also aware that I have not provided the reader with a discussion of the role of power in Peircean semiotics and that pragmatist philosophy is not considered as being aligned with critical theory (Olteanu, 2019). Yet, theorising develops semiotic-dialogic insights into visual literacies of AR through engaging with some of the key theorists of dialogic pedagogy. In the spirit of dialogism, I hope that it might also contribute to posing new questions, further generation of meaning and new naming of the world. Semiotic-dialogism adheres to Bakhtin's (1986) commitment to an infinite chain of questioning within dialogue and Peirce's (1878) perpetual enquiry within the ongoing meaning making of collaboration and semiosis. The study thus contributes a further chain of theorising and questioning, surrounding semiotic-dialogic pedagogy, to you, a reader. Learners, teachers, researchers and theorists therefore intersect as critical co-investigators and through dialogue.

For future studies, semiotic-dialogism could explore the power-driven dimension of language, speech and dialogism and nurture the study's embryonic questions. These questions might consider the extent to which dialogic pedagogy develop vocabulary and critical conversations to challenge patriarchy, (neo)colonial discourses and the nexus of hyper-inequalities. Developing critical visual literacies might also give voice, albeit verbal, visual or technological, to learners on the margins of power. Admittedly, this theoretical study leaves a great number of questions unanswered. Nevertheless, I would like to emphasise that an important aspect of the semiotic-dialogic theorising is the process of semiosis for establishing questions surrounding dialogic-pedagogy. But gaps and the lack of adequate theorising of the multimodality of AR or semiotic-dialogic perspectives of technology more generally remain. These gaps mitigate against the formation of critical questions at various levels of learning and theorising. Nevertheless, theorising in this study begins to develop discussion about the visual turn in dialogic pedagogies. It offers a counter narrative to understanding technologies, including $A R$, in terms of technological solutionism, individualised learning and the one-directional transmission of knowledge.

Finally, semiotic-dialogic inquiry considers the signs, filters, form, living codes of learning. These filters, or sign vehicles, include histories, cultures, languages, images, modalities but also teachers, learners, technologies, researchers, theories and theorists. Since pedagogies occur across diverse and multicultural environments, semiotic-dialogic pedagogy articulates the crucial role of dialogue and semiosis within complex visual literacies and technologies of learning.

\section{References}

Adobe (2020) Creative Cloud for schools, universities, institutions / https://www.adobe.com/mena en/creativecloud/buy/education.html?sdid=B16P4299\&mv=search \&ef id=Cj0KCQjwufn8BRCwARIsAKzP697bnnh8RZdfObBxPvmRriCvrNoB2MTZYpgUwyel5akO wc- 
dmINUZUYaAiTIEALw wcB:G:s\&s kwcid=AL!3085!3!397323857730!e!!g!!adobe\%20creative\%2 0cloud\%20education!1677056358!71951618824

Aronowitz, S. (2015). Against orthodoxy: Social theory and its discontents. New York: Palgrave and MacMillan.

Bakhtin, M. (1986). Rabelais and his world. Bloomington: Indiana University Press.

Bakhtin, M. (1999). The problem of speech genres. In A. Jaworski \& N. Coupland, The discourse reader (pp. 121 - 132). London and New York: Routledge. Taylor \& Francis Group.

Bergman, M. (2009). Peirce's philosophy of communication. The rhetorical underpinnings of the theory of signs. London: Continuum.

Cassidy, M., \& Knowlton, J. (1983). Visual literacy: A failed metaphor?. ECTJ, 31(Michael F. Cassidy \& James Q. Knowlton), 67-90.

Cresswell, J. (2016). Disengagement, pedagogical eros and (the undoing of?) Dialogic pedagogy. Dialogic Pedagogy: An International Online Journal, 4. doi: 10.5195/dpj.2016.182

Debes, J. (1969). The Loom of Visual Literacy--An Overview. Audiovisual Instrument, 14(8), 25-7.

Dewey, J. (1922). Human nature and conduct. New York: Henry Holt and Company.

Denzin, N. (2001). The reflexive interview and a performative social science. Qualitative Research, 1(1), 23-46. https://doi.org/10.1177/146879410100100102

Di Serio, A., Ibáñez, M., \& Kloos, C. (2013). Impact of an augmented reality system on students' motivation for a visual art course. Computers \& Education, 68, 586-596. doi: 10.1016/j.compedu.2012.03.002

Dori, Y., \& Belcher, J. (2005). How does technology-enabled active learning affect undergraduate students' understanding of electromagnetism concepts?. Journal of The Learning Sciences, 14(2), 243-279. doi: 10.1207/s15327809jls1402_3

Dunleavy, M. (2014). Design principles for augmented reality learning. Techtrends, 58(1), 28-34. doi: 10.1007/s11528-013-0717-2

Dunleavy, M., Dede, C., \& Mitchell, R. (2009). Affordances and limitations of Immersive participatory augmented reality simulations for teaching and learning. Journal Of Science Education And Technology, 18(1), 7-22. doi: 10.1007/s10956-008-9119-1

Freire, P. (1970). Pedagogy of the oppressed (11th ed.). London: The Continuum Publishing Company.

Freire, P. (1978). Pedagogy in process: The letters to Guinea-Bissau.. New York: Seabury Press.

Freire, P. (1998). Pedagogy of Freedom: Ethics, Democracy, and Civic Courage. Lanham: Rowman \& Littlefield Publishers.

Freire, P., \& Macedo, D. (1987). Literacy: Reading the word \& the world. South Hadley: Mass.: Bergin \& Garvey Publishers.

Hoban, C., Hoban, C., \& Zissman, S. (1937). Visualising the Curriculum. New York: Dryden press.

Hurley, Z. (2016). WoW! Window on the World: IPADS and Augmented Reality for Richer Readings. In Academic Oasis International Multidisciplinary Academic Conference. Miami: Academic Oasis International Multidisciplinary Academic Conference.

Hurley, Z. (2018). Book review: Introducing multimodality. Learning and Teaching in Higher Education: Gulf Perspectives, 15(1). doi: 10.18538/lthe.v15.n1.311 
Hurley, Z. (2019a). Imagined affordances of Instagram and the fantastical authenticity of Gulf-Arab social media influencers. Social Media + Society, 5 (1).

Hurley, Z. (2019b). Why I no longer believe social media is cool . . Social Media + Society, 5(3). doi: $10.1177 / 2056305119849495$

Hurley, Z. (2021). Dialogic theorising of Emirati women's technology enhanced learning in the United Arab Emirates. Studies in Technology Enhanced Learning. doi: 10.21428/8c225f6e.b70d4b5a

Ivanov, G., \& Ivanov, M. (2011). Enhancement of learning and teaching in computer graphics through marker augmented reality technology. International Journal of New Computer Architectures And Their Applications, 1(1), 176 - 184.

Jay, M. (1988). The rise of hermeneutics and the crisis of ocularcentrism. Poetics Today, 9(2), 307. doi: $10.2307 / 1772691$

Lacković, N. (2020). Inquiry graphics in higher education. Springer Nature.

Lotman, J. (2005). On the semiosphere. Sign Systems Studies, 33(1), 205-229. doi: 10.12697/sss.2005.33.1.09

Mahadzir, N., \& Phung, L. (2013). The use of augmented reality pop-up book to increase motivation in English language learning for national primary school. IOSR Journal of Research \& Method In Education (IOSRJRME), 1(1), 26-38. doi: 10.9790/7388-0112638

Martin-Gutierrez, J., \& Fernández, M. (2014). Augmented reality environments in learning, communicational and professional contexts in higher education. Digital Education Review, (26).

Matusov, E. (2009). Journey into dialogic pedagogy. Hauppauge, NY: Nova Science Publishers.

Matusov, E. (2020). Pattern-recognition, intersubjectivity, and dialogic meaning-making in education. Dialogic Pedagogy: An International Online Journal, 8. doi: 10.5195/dpj.2020.314

Matusov, E., \& Marjanovic-Shane, A. (2017). Bakhtin's mystical organic holism and its consequences for education. Dialogic Pedagogy: An International Online Journal, 5. doi: 10.5195/dpj.2017.222

Matusov, E., von Duyke, K., \& Kayumova, S. (2015). Mapping concepts of agency in educational contexts. Integrative Psychological And Behavioral Science, 50(3), 420-446. doi: 10.1007/s12124-015-9336-0

Mead, G. (1934). Mind, Self \& Society. Chicago and London: The University of Chicago Press.

Means, A. (2018). Learning to save the future. New York: Routledge.

MIT. (2021). John Werner | MIT Connection Science. Retrieved 7 July 2021, from http://connection.mit.edu/john-werner

Mirzoeff, N. (2006). On visuality. Journal of Visual Culture, 5(1), 53-79. https://doi.org/10.1177/1470412906062285

Olteanu, A. (2015). Philosophy of education in the semiotics of Charles Peirce. Oxford: Peter Lang.

Olteanu, A. (2019). Multiculturalism as multimodal communication. Cham: Springer International Publishing.

Peirce, C. (1867). C. S. Peirce Manuscripts | FromThePage. Retrieved 5 October 2019, from https://www.fromthepage.com/display/search?utf8=\%E2\%9C\%93\&collection_id=16\&search_strin $\mathrm{g}=1868 \&$ button $=$

Peirce, C. (1878). How to make our ideas clear. Popular Science Monthly, 12(Jan), 286 - 302. 
Peirce, C. (1908). The essential Peirce. Bloomington, Indiana: Indiana University Press.

Peirce, C. (1931). The collected papers of Charles Sanders Peirce, Vol. I: The principles of philosophy. Cambridge: Harvard University Press.

Petrilli, S. (2017). Challenges to living together: Transculturalism, migration, exploitation for a semioethics of human relations. Milan: Mimesis International.

Pettersson, R. (1989). Visuals for information, research and practice (p. 146). Educational Technology Publications.

Roberts, P. (2003). Pedagogy, neoliberalism and postmodernity: Reflections on Freire's later work. Educational Philosophy And Theory, 35(4), 451-465. doi: 10.1111/1469-5812.00041

Semetsky, I., \& Stables, A. (2014). Pedagogy and edusemiotics: Theoretical challenges/practical opportunities. Vol. 62: Springer.

Solak, E., \& Cakır, R. (2015). Exploring the effect of materials designed with augmented reality on language learners' vocabulary learning, 13(2). Retrieved from http://files.eric.ed.gov/fulltext/EJ1068381.pdf

Speicher, M. (2018). What is augmented reality, anyway?. Retrieved 7 July 2021, from https://theconversation.com/what-is-augmented-reality-anyway-99827

Stables, A., Nöth, W., Olteanu, A., Pesce, S., \& Pikkarainen, E. (2018). Semiotic theory of learning. London: Routledge.

Strand, T. (2010). The making of a new cosmopolitanism. Studies in Philosophy and Education, 29(2), 229-242. doi: 10.1007/s11217-009-9161-3

Wegerif, R. (2017) Defining 'dialogic education'. Retrieved 3 March 2020, from https://www.rupertwegerif.name/blog/defining-dialogic-education

Werner, J. (2019). How augmented reality can give us superpowers | John Werner | TEDxMidAtlantic. Retrieved 7 July 2021, from https://www.youtubei: 10.1016/j.procs.2015.09.277

\section{(cc) EY}

New articles in this journal are licensed under a Creative Commons Attribution 4.0 United States License.

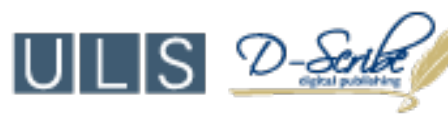

This journal is published by the University Library System, University of Pittsburgh as part of its D-Scribe Digital Publishing Program and is cosponsored by the University of Pittsburgh Press. 